\title{
Participatory ergonomic improvements in small enterprises in some countries in Asia
}

\author{
Kazutaka KOGI and Tsuyoshi KAWAKAMI \\ Institute for Science of Labour, Kawasaki, Japan
}

\begin{abstract}
Under the rapid industrialization in Asia, participatory approaches have been used as a practical means of ergonomic improvements in small enterprises. Recent experiences confirm that participatory training and research activities can lead to concrete results including ergonomic workplace improvements in different socio-cultural conditions. These participatory activities have been known to be successful when they focus on (1) learning from local good examples, (2) group work methods for identifying feasible solution by the local people and (3) developing practical intervention tools. It is concluded that participatory ergonomic approaches have a large potential for changing workplaces in terms of the safety, health and well-being of workers in small enterprises.
\end{abstract}

\section{BACKGROUND}

For the last several years, ergonomic improvements in small enterprises have been promoted in collaboration with occupational safety and health institutions in some countries in Asia ${ }^{1-4)}$. This has led to the development of an inter-country network for improving the health of small enterprise workers. Participatory steps based on the exchange of positive local experiences have proven to be effective in various socio-cultural settings.

Based on these experiences, the special need for utilizing practical intervention tools for identifying workplace needs and available solutions is reviewed and discussed. These tools are effective when they can facilitate the participatory process of local people. This review study confirms the importance of (a) building on local practice and practical workplace improvements and (b) promoting participatory processes.

This study summarized the recent results of ergonomic interventions we conducted in collaboration with research and health service institutions in some countries in Asia. All these institutions are active members of our inter-country network for field ergonomics. The interventions reviewed and counterpart institutions included: a workplace improvement project for small and medium- sized enterprises in Samutprakarn,
Thailand 2) (Occupational Health Training and Demonstration Centre); (b) intervention studies in medium-sized factories in Malaysia ${ }^{4}$ ) (Department of Community Health, Universiti Kebangsaan Malaysia); (c) intervention studies in a rural district in the Mekong Delta area of Vietnam3) (District and Provincial Health Offices); and (d) a work-improvement in small enterprises (WISE) project in four regions in the Philippines6) (Bureau of Working Conditions, Department of Labor and Employment). All these interventions were aimed at improving working conditions and the working environment in small and medium sized enterprises by applying participatory methods similar to those developed for WISE training activities.

\section{BUILDING ON LOCAL PRACTICE}

The advantage of building on local practice, in particular learning from locally achieved improvements, was apparent throughout these interventions. Despite large differences in socioeconomic and cultural conditions among the participating countries, the key for successful interventions was to learn from local positive example. The presentation of locally achieved improvements could facilitate new interventions from occupational health and ergonomics points of view. These local improvements had strikingly similar features despite large between-country differences in local situations. 
Table 1. Number of improvements achieved by participatory work improvement training courses for small and medium-sized enterprises in India and the Philippines 1 ).

\begin{tabular}{lccccccc}
\hline & \multicolumn{2}{c}{ Madras, India (27 enterprises) } & \multicolumn{3}{c}{ Cebu, the Philippines (24 enterprises) } \\
\cline { 6 - 8 } Technical area & Planned & $\begin{array}{l}\text { Done or in } \\
\text { progress }\end{array}$ & $\begin{array}{c}\text { To be } \\
\text { done }\end{array}$ & & Planned & $\begin{array}{l}\text { Done or in } \\
\text { progress }\end{array}$ & $\begin{array}{l}\text { To be } \\
\text { done }\end{array}$ \\
\hline Materials storage-handling & 8 & 4 & 3 & 19 & 15 & 4 \\
Workstation design & 5 & 4 & 1 & 20 & 12 & 8 \\
Machine safety & 6 & 4 & 2 & 7 & 7 & - \\
Lighting & 11 & 9 & 2 & 11 & 7 & 4 \\
Controlling chemicals & 11 & 11 & - & 16 & 12 & 4 \\
Premises & 19 & 14 & 3 & 21 & 16 & 5 \\
Welfare facilities & 8 & 8 & - & 8 & 5 & 3 \\
Work organization & 2 & 2 & - & 6 & 3 & 3 \\
\hline \multicolumn{1}{c}{ Total } & 70 & 56 & 11 & 108 & 77 & 31 \\
$\quad \%)$ & $(100)$ & $(80)$ & $(16)$ & $(100)$ & $(71)$ & $(29)$ \\
\hline
\end{tabular}

The Work Improvement in Small Enterprises (WISE) methodology was used for each course.

Collected improvement examples found in the local workplaces have been useful in various ways. These local examples were particularly useful when they were used in: discussion of such examples in orientation meetings; encouraging voluntary initiative; case study sessions; clues for the identification of multiple problem areas; discussing available solutions; and providing support for prioritizing action. It should be emphasized that such examples could be used in a number of phases in field interventions. The role of local good examples could be summarized as a practical means of information-sharing with a view to: (a) identifying local needs; (b)understanding benefits of interventions; (c) motivating local people for taking action; and (d) focusing on available solutions.

This facilitating role of local good examples was in conformity with the positive experiences through the application of the Work Improvement in Small Enterprises (WISE) methodology developed by the ILO for enabling small enterprises to carry out improvements1), 5), 6). For implementing the practical improvements, the WISE methodology prioritized eight technical areas including (1) materials storage and handling, (2) work-station design, (3) productive machine safety, (4) control of hazardous substances, (5) lighting, (6) work-

related welfare facilities, (7) premises and (8) work organisation. All these technical areas adopted in WISE were found essential by our participating institutions for implementing immediate improvements in different local conditions.

Our experiences confirmed the common types of improvements conducive to field interventions. Interventions tended to be successful when improvements aimed at were: (a) relatively simple; (b) available at low cost; (c) multifaceted; (d) combined with visible benefits; (e) flexibly adjusted to local situation; and (f) accessible by using local materials and skills.

Low-cost improvements were usually simple and this simplicity apparently helped create opportunities for action and achieve immediate results7). The multifaceted nature of achieved practical improvements seemed particularly important ${ }^{8}$ ). Main types of such improvements were typically seen in materials handling, workstation design, physical environment, welfare facilities and work organization (Table 1). 


\section{PROMOTING PARTICIPATORY PROCESSES}

In organizing ergonomic interventions, a special attention was paid to their participatory nature9). In view of the many constraints, particularly in developing countries, taking practical steps for finding locally workable solutions was crucial. This was because occupational health and ergonomic interventions had to be a local process responding to the particular needs of local people10).

Our experiences also showed that the best way to facilitate participatory processes was to focus on group work aimed at solutions. Participatory approaches have been largely adopted in ergonomic training and research activities. WISE methodology utilized the benefits of group work for increasing the local initiative for the substantial improvements. The participatory training approaches similar to WISE have been practiced in different socio-cultural settings. In the Philippines, WISE has been integrated into the existing labour policy and many labour inspectors have been mobilized to work as the WISE trainers6). In Malaysia, the training was successful for meeting the specific needs of the safety personnel of the local enterprises and construction companies 4 ). In Thailand, the participatory approaches have gained popularity as an essential tool for improving safety and health of small enterprises 2). In Pakistan, local trade unions have successfully conducted participatory training courses 11 ). In Vietnam, the participatory training courses have been applied to the joint improvement of the working conditions and living conditions of rural workers 3 ).

To sustain active initiative of local research staff and workplace people, direct support was needed for group work in sharing experiences and identifying workable solutions. The practical steps commonly used for facilitating participatory interventions included:

(a) group discussion and subsequent group action based on locally achieved examples;

(b) prioritizing different elements of the workplace by group inspections; and

(c) identifying simple improvements first with a view to learning-by-doing.

Good local examples and workplace assessment results were useful inputs so as to help the participants identify locally available solutions.

Based on the successful experiences of group work processes in pilot intervention studies, we could jointly organize a series of participatory action training workshops for workplace improvements2), 4), 11). A workshop of 2-3 days could usually motivate trainees to learn from local good examples, examine their own workplace conditions by means of a checklist, and identify feasible lowcost solutions in multiple aspects. This training approach was similar to the WISE methodology. It was particularly interesting to see that such participatory training could motivate both research staff and workplace people together.

This experience led to the recognition of the importance, within the network, of developing participation tools that could facilitate the assessment of workplace needs and the identification of practical workplace improvements. The use of action checklists listing feasible actions, combined with small group work, was considered to be extremely effective in prioritizing different workplace aspects and focusing on available solutions. As the most essential tools the following may be mentioned:

(a) audio-visual materials of local low-cost improvements;

(b) action checklists that list locally available simple solutions;

(c) action manuals providing guidance as to how to implement improvements;

(d) practical methods to animate group work (such as brainstorming, games, etc.);

(e) work sheets for group work and presentation (photo-sheets, flip-charts, etc.).

Participatory approaches have also been applied to the field ergonomic researches for developing the practical improvement ideas based on the research 
finding3), 12). Combined with the widelyapplicable field study methods such as actionchecklists, direct observation of the working conditions or monitoring of fatigue symptoms of workers, group work methods have been found effective for developing feasible improvement plans. It is of particular interest that rapid feedback of the research results to the local workplaces could enhance the participatory process for initiating improvement actions 3 ), 12).

It should be noted that, in order to initiate an effective participatory process, providing a forum of discussion by local people was by no means sufficient. Participants had to be given an opportunity to do the planning and implementation of improvements. Thus, it was very important to enable participants to base their judgement on information on local achievements and locally available solutions. The above-mentioned tools were closely coupled with this idea of direct participation

\section{CONCLUSIONS}

Our experiences of several years in developing a small network for field interventions promoting practical improvements of workers 1 health and ergonomics demonstrated the importance of building on local practice as well as promoting participatory action. Particularly important was a combination of (a) presenting locally achieved improvements; (b) group work methods; and (c) using participatory tools. A clear focus on identifying and implementing low-cost improvements was always essential.

\section{REFERENCES}

1) Kogi, K.: Participatory ergonomics that builds on local solutions, J. Human Ergol., 24, 37-45, 1995.

2) Tandhankul, N., Yuangsaard, S., Pongpanich, C., Punpeng, T., Punngok,A., Juengprasert, W., and Kawakami, T.: Experiences of successful action programmes for occupational health, safety, and ergonomics promotion in small scale enterprises in
Thailand. J. Human Ergol., 24, 105-115, 1995.

3) Kawakami, T. and Khai, T.T.: Improving safety and health at work in rural sugar cane factories in the Mekong Delta Area in Vietnam, J. Japan Assoc. for International Health, 10, 199-201, 1996.

4) Rampal, K.G., Kogi, K., Che Man, A.B., Chaikittiporn, C., Ismail,N.H., Kawakami,T. and Musri, M. : Experiences of action-oriented field ergonomics training in Malaysia. J. Science of Labour, 72 (Part II of 2 Parts), 24-30, 1996.

5) Thurman, J.E., Louzine, A.E. and Kogi, K.:

Higher productivity and a better place to work. Trainers' manual : International Labour Office, Geneva, 1988.

6) Torres, C.I. and Conferido, D. R. Effective support for participatory work improvement programmes in small and medium-sized enterprises. In: the abstract book on the International Symposium on Common Strategies for HumanCentred Work -Enterprise-level Action Programmes for Making Work More Human -, Tokyo, 1996.

7) Kogi, K., Phoon,W.O. and Thurman, J.E.: Lowcost way of improving working conditions: 100 examples from Asia. International Labour Office, Geneva, 1988.

8) Kogi, K.: Improving working conditions in small-enterprises in developing Asia. International Labour Office, Geneva, 1985.

9) Noro, K. and Imada, A. (eds.): Participatory ergonomics, Taylor and Francis, London, 1991.

10) Kogi, K., and Sen, R.N.: Third world ergonomics, International Reviews of Ergonomics, 1, 77-118, 1987.

11) Shimizu, H. : Participatory training for improving occupational safety and health by trade union initiatives in developing countries. In: the abstract book on the International Symposium on Common Strategies for Human-Centred Work Enterprise-level Action Programmes for Making Work More Human -, Tokyo, 1996.

12) Kawakami, T and Chaikittiporn, C. :

Developing interactive support mechanisms for improving safety and health in some industries in Thailand, Environmental Sciences, 1996. (in press) 